\title{
Incidence, Risk Factors, and Comorbidities of Vocal Cord Paralysis After Surgical Closure of a Patent Ductus Arteriosus: A Meta-analysis
}

\author{
Brandon Michael Henry ${ }^{1,2}$ (D) Wan Chin Hsieh ${ }^{2,4} \cdot$ Beatrice Sanna ${ }^{2} \cdot$ Jens Vikse ${ }^{2,5}$. Dominik Taterra ${ }^{2,3}$. \\ Krzysztof A. Tomaszewski ${ }^{2,3}$
}

Received: 26 March 2018 / Accepted: 16 August 2018 / Published online: 24 August 2018

(c) The Author(s) 2018

\begin{abstract}
Surgical closure of a patent ductus arteriosus (PDA) is considered standard treatment for symptomatic neonates refractory to medical therapy. Sometimes, iatrogenic injury to the left recurrent laryngeal nerve during the procedure can result in vocal cord paralysis (VCP). This study aimed to estimate the incidence of VCP in patients after surgical PDA closure and to identify any associated risk factors and morbidities associated with VCP in the preterm infant population. A thorough search of the major electronic databases was conducted to identify studies eligible for inclusion into this meta-analysis. Studies reporting data on the incidence of VCP (primary outcomes) or risk factors and morbidities associated with VCP in premature infant population (secondary outcomes) were included. A total of 33 studies $(n=4887$ patients) were included into the analysis. Overall pooled incidence estimate of VCP was 7.9\% (95\% CI 5.3-10.9). The incidence of VCP after PDA closure was significantly much higher in premature infants $(11.2 \%$ [95\% CI 7.0-16.3]) than in non-premature patients $(3.0 \%$ [95\% CI 1.5-4.9]). The data showed that VCP was most common after surgical ligation and in studies conducting universal laryngoscopy scoping. The risk factors for postoperative VCP in preterm infants included birth weight and gestational age. In addition, VCP was significantly associated with the occurrence of bronchopulmonary dysplasia, gastrostomy tube insertion, and increased duration of mechanical ventilation. Vocal cord paralysis remains a frequent complication of surgical closure of a PDA, especially in premature neonates, and is associated with significant post-procedural complications.
\end{abstract}

Keywords Patent ductus arteriosus $\cdot$ Recurrent laryngeal nerve injury $\cdot$ Vocal cord paralysis $\cdot$ Meta-analysis

Electronic supplementary material The online version of this article (https://doi.org/10.1007/s00246-018-1967-8) contains supplementary material, which is available to authorized users.

Brandon Michael Henry

bmhenry55@gmail.com

1 Division of Cardiology, Cincinnati Children's Hospital Medical Center, Cincinnati, OH, USA

2 International Evidence-Based Anatomy Working Group, 12 Kopernika St 31-034 Kraków, Poland

3 Department of Anatomy, Jagiellonian University Medical College, Kraków, Poland

4 First Faculty of Medicine, Charles University, Prague, Czech Republic

5 Department of Surgery, Stavanger University Hospital, Stavanger, Norway

\section{Introduction}

The normal ductus arteriosus arises from the left pulmonary artery and connects to the transition area between the aortic arch and descending aorta just distal to the origin of the left subclavian artery. Physiologically, ductus arteriosus closes shortly after birth to facilitate proper breathing in the infant. Rarely it narrows and occludes prematurely during fetal life. It is estimated that 8 out of 1000 preterm infants will develop a patent ductus arteriosus (PDA), a condition in which the ductus arteriosus fails to close postnatally [1].

The presence of PDA is reported to contribute to the development of feeding intolerance, necrotising enterocolitis, intracranial hemorrhage, decreased glomerular filtration rate, and bronchopulmonary dysplasia (BPD) in preterm infants [2]. Initial treatment of PDA is usually pharmacological and includes indomethacin. Surgical closure is considered a standard treatment for symptomatic neonates refractory to medical therapy $[3,4]$. During the surgical procedure, 
the perineurium of the left recurrent laryngeal nerve may be disrupted or the nerve may be contused or injured by the clip or ligature [5]. A possible adverse event of such an injury is vocal cord paralysis (VCP). Duration of vocal cord dysfunction is variable and may be transient $(<1$ year) or persistent (>1 year) [6].

Though VCP following PDA surgical closure is well reported in the literature, the recorded incidence of this postoperative complication varies widely, ranging from $>1$ to $64 \%[7,8]$. Previous research provided inconclusive data on its incidence due to different methodology of assessment of VCP and variable laryngoscopy scoping. As such, there was a need for a study that would unify the existing data on the incidence of VCP based on the method used to close PDA, method to assess VCP, and evaluate the influence of age and ethnic origin on patient outcome. Therefore, the objective of this meta-analysis was to estimate the incidence of VCP after surgical PDA closure in different age populations (primary outcomes), as well as identify associated risk factors and morbidities for preterm infants (secondary outcomes).

\section{Materials and Methods}

\section{Search Strategy}

A search of the major electronic databases, including PubMed, ScienceDirect, EMBASE, BIOSIS, SCIELO, CNKI, and Web of Science, was performed in order to identify potential studies for inclusion in the meta-analysis. No date limits or language restrictions were applied. Search terms included patent ductus arteriosus and a selection of one of the following: recurrent laryngeal nerve or vocal cord paralysis or vocal cord paresis or vocal fold dysfunction. The references of the included studies were also searched in order to identify additional articles. The authors strictly adhered to the Preferred Reporting Items for Systematic Reviews and Meta-Analyses (PRISMA) guidelines (see Supplementary material 1).

\section{Study Selection Criteria}

Studies were included into the meta-analysis if (1) reported clear, extractable data on the incidence of the VCP after PDA closure, (2) the study clearly defined VCP as unilateral vocal cord immobility, and (3) used clip or ligation technique for PDA closure. Meta-analysis of risk factors in preterm infants additionally included the following criteria (1) study population included preterm infants that underwent surgery for PDA, (2) outcomes reported included incidence of VCP risk factors and associated comorbidities. The following exclusion criteria were employed: (1) case studies, case reports, conference abstracts, and letters to the editor, (2) studies reporting incomplete data. Two independent reviewers assessed the eligibility of the articles for the inclusion into the meta-analysis. Any discrepancies among reviewers were resolved by a consensus among the entire review team. In case of studies published in languages other than English, medical professionals fluent in English and the original language of the article translated the texts.

\section{Data Extraction and Quality Assessment}

The following data were extracted from the eligible studies: year, country, type of study and technique of PDA closure (suture ligature or clipping), sample size (number of patients), incidence of VCP, length of injury-transient or permanent (transient VCP was defined as lasting less than a year, while persistent as more than a year), patients' characteristics (age, geographical origin). Patients were divided into two groups-premature newborns/low birth weight newborns and non-premature patients (any patients that did not fit into first group). Data from any study comparing different cohorts of patients (i.e., ligation vs. clip, premature vs. non-premature patients) were extracted and treated as two separate studies for the purpose of analysis. Whenever possible, outcomes comparing VCP and non-VCP groups in premature/low birth weight patients were also extracted. These included the following: birth weight, weight at the time of surgery, age (days) at the time of surgery, gestational age, incidence of bronchopulmonary dysplasia, total days of mechanical ventilation, and incidence of gastrostomy tube insertion. Critical Appraisal of the Health Research Literature tool was used to assess the quality of studies reporting the prevalence or incidence of a health problem [9]. Study quality was rated on a scale from 1 (very poor) to 8 (high). In case of any discrepancies in the data of included studies, the review team attempted to contact the authors of the original study for clarification.

\section{Statistical Analysis}

Pooled incidence estimates were calculated using random effects model with MetaXL version 5.3 by EpiGear International Pty Ltd (Wilston, QLD, Australia). Subgroup analysis based on type of PDA closure and geographical distribution of the studies was performed to probe the source of heterogeneity. Confidence intervals were used to compare the incidence rates, with any overlap between two groups indicating a lack of statistical significance.

Continuous outcomes in risk factors analysis were analyzed by calculating weighted mean difference (WMD) with the $95 \%$ confidence intervals (95\%CI). Dichotomous outcomes were analyzed by calculating relative risk (RR) with the 95\%CI. Reported values were two-tailed, and 
hypothesis-testing results were considered statistically significant at $p<0.05$.

Heterogeneity among included studies was assessed with the $\chi^{2}$ test and the $I^{2}$ statistic. A Cochran's $\mathrm{Q} p$ value of $<0.10$ indicated significant heterogeneity [10]. The following intervals were used to analyze heterogeneity in $I^{2}$ statistic: 0-40\%—-might not be important; 30-60\%—might indicate moderate heterogeneity; 50-90\%-may indicate substantial heterogeneity; and 75-100\% may represent considerable heterogeneity [10].

\section{Results}

\section{Literature Search}

The study identification flow chart is presented in Fig. 1. The initial electronic search yielded 257 potential articles. Additional two articles were identified through reference search. After eligibility analysis, 30 articles were included in this meta-analysis.

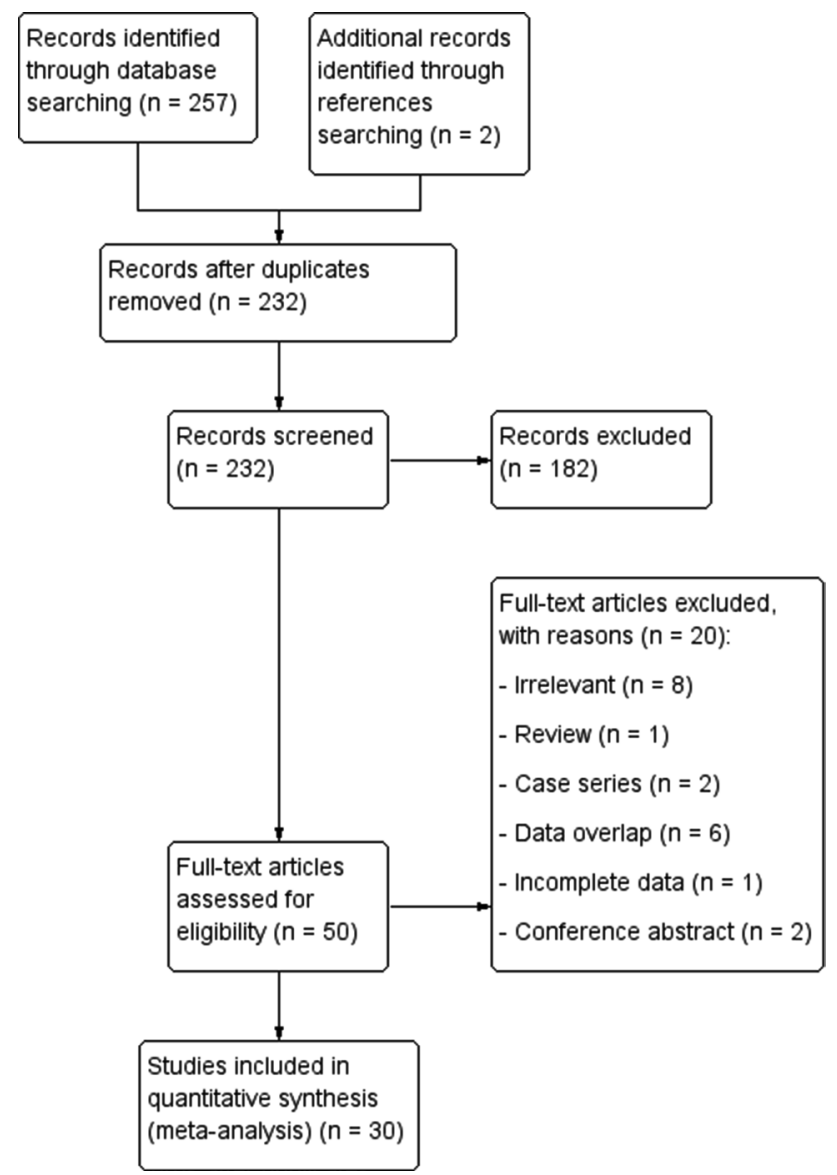

Fig. 1 Study identification flowchart

\section{Characteristics of the Eligible Studies}

The characteristics of included studies with quality assessment are presented in Table 1. Due to the fact that three articles [11-13] compared two different cohorts of patients, each cohort was treated as a separate study, therefore 33 studies ( $n=4887$ subjects) were included into this metaanalysis. Specifically, the study by Davis et al. [11] contained two groups of patients, one treated by ligation and one by clip method, and thus for the purposes of analysis was considered as two separate studies. The study by Spanos et al. [12] was treated as two separate studies for the same reason. The study by Villa et al. [13] analyzed two groups of patients (low birth weight and non-premature patients), thus it was also treated as two separate studies during analysis.

In total, fourteen studies were prospective and the other nineteen were retrospective. Ligation was the most frequently used surgical closure approach. Only one study analyzed all patients with laryngoscopy preoperatively. A total of seven studies scoped all patients postoperatively with laryngoscopy to assess for VCP. All of those studies used a surgical approach and 6/7 analyzed premature patients. Ten studies utilized selective scoping with laryngoscopy of patients that showed symptoms suggestive of VCP. Sixteen studies identified patients with VCP based only on symptoms or method was not mentioned.

\section{Overall Incidence of VCP}

A total of 33 studies ( $n=4887$ subjects) reported extractable data on the incidence of VCP in all age populations after PDA closure (Table 2). Overall pooled incidence estimate of VCP was 7.9\% (95\%CI 5.3-10.9) (Fig. 2).

VCP occurred most often in patients treated with surgical ligation (11.1\%; [95\%CI 7.2-15.8]). Surgical clipping caused significantly less VCP than surgical ligation, with pooled VCP incidence rate of $2.4 \%$ (95\% CI 1.3-3.9). Analysis of studies assessing all patients postoperatively with laryngoscopy (24.2\% [95\%CI 14.5-35.3]) showed significantly higher pooled incidence of VCP than studies that diagnosed VCP based only on symptoms $(2.2 \%$ [95\% CI 1.3-3.3], Table 2) or studies assessing only symptomatic patients (9.1\% [95\% CI 4.2-15.6]).

Geographical analysis revealed that VCP after PDA closure occurred more often in North America (11.5\% [95\% CI 7.4-16.5]) than in Europe (4.5\% [95\% CI 2.3-7.3]) or Asia (1.0\% [95\%CI 0.5-1.6]).

\section{Incidence of VCP in Premature/Low Birth Weight Patients}

Twenty-two studies ( $n=1895$ patients) were included in the analysis on the incidence of VCP after PDA closure 
Table 1 Characteristics of included studies

\begin{tabular}{|c|c|c|c|c|c|c|c|c|}
\hline Study ID & Country & Study design & $\begin{array}{l}\text { Type of PDA } \\
\text { closure }\end{array}$ & $\begin{array}{l}\text { Method to assess } \\
\text { VCP }\end{array}$ & Premature & $\begin{array}{l}\text { Num- } \\
\text { ber of } \\
\text { patients }\end{array}$ & $\begin{array}{l}\text { Incidence } \\
\text { of VCP } \\
(\%)\end{array}$ & Study quality \\
\hline Benjamin et al. [5] & USA & Prospective & Ligation & Selective scoping ${ }^{\mathrm{b}}$ & Yes & 55 & 40.0 & 7 \\
\hline Bensky et al. [14] & USA & Prospective & Clip & Selective scoping & Yes/No & 118 & 2.5 & 6 \\
\hline Burke et al. [15] & USA & Prospective & Ligation & Symptoms only ${ }^{\mathrm{a}}$ & Yes & 34 & 2.9 & 6 \\
\hline Carpes et al. [16] & Canada & Prospective & Ligation & $\begin{array}{l}\text { Pre-op and post-op } \\
\text { universal scoping }\end{array}$ & No & 42 & 16.7 & 6 \\
\hline Clement et al. [17] & Canada & Retrospective & Ligation & Universal scoping $^{c}$ & Yes & 23 & 52.2 & 6 \\
\hline Davis et al. [11] & USA & Retrospective & Ligation & Selective scoping & Yes & 68 & 4.4 & 5 \\
\hline Davis et al. [11] & USA & Retrospective & Clip & Selective scoping & Yes & 38 & 0.0 & 5 \\
\hline Ekici et al. [18] & Turkey & Retrospective & Ligation & Symptoms only & Yes & 12 & 8.3 & 6 \\
\hline Hawkins et al. [36] & USA & Retrospective & Ligation & Symptoms only & No & 20 & 5.0 & 5 \\
\hline Heuchan et al. [19] & England & Retrospective & Ligation & Symptoms only & Yes & 125 & 4.8 & 6 \\
\hline Hines et al. [20] & USA & Retrospective & Clip & Selective scoping & Yes & 100 & 5.0 & 6 \\
\hline Ibrahim et al. [21] & Egypt & Retrospective & Ligation & Symptoms only & Yes & 120 & 0.8 & 5 \\
\hline Kang et al. [22] & England & Prospective & Ligation & Symptoms only & Yes & 102 & 2.0 & 6 \\
\hline Laborde et al. [23] & France & Retrospective & Clip & Symptoms only & No & 332 & 1.8 & 6 \\
\hline Liem et al. [24] & Vietnam & Prospective & Clip & Symptoms only & No & 58 & 0.0 & 5 \\
\hline $\begin{array}{l}\text { Mandhan et al. } \\
\text { [25] }\end{array}$ & New Zealand & Retrospective & Ligation and clip & Symptoms only & Yes & 145 & 0.7 & 6 \\
\hline Nezafati et al. [26] & Iran & Retrospective & Clip & Symptoms only & No & 1300 & 1.0 & 6 \\
\hline Nichols et al. [27] & USA & Retrospective & Ligation & Selective scoping & Yes & 532 & 12.4 & 5 \\
\hline Niinikoski et al. [3] & Finland & Retrospective & Surgical & Symptoms only & Yes & 101 & 1.0 & 5 \\
\hline Odegard et al. [28] & USA & Prospective & Clip & Symptoms only & No & 60 & 1.7 & 5 \\
\hline Pereira et al. [29] & USA & Prospective & Ligation & Universal scoping & Yes & 61 & 11.5 & 5 \\
\hline Pharande et al. [30] & Australia & Retrospective & Ligation & Selective scoping & Yes & 35 & 31.4 & 6 \\
\hline Roksund et al. [8] & Norway & Prospective & Surgical & Universal scoping & Yes & 11 & 63.6 & 7 \\
\hline Rukholm et al. [31] & Canada & Retrospective & Ligation & $\begin{array}{l}\text { Only } 31 / 111 \\
\text { patients had LAR } \\
\text { post-op }\end{array}$ & Yes & 111 & 17.1 & 7 \\
\hline Smith et al. [32] & USA & Prospective & Ligation & Universal scoping & Yes & 86 & 16.3 & 6 \\
\hline Sørensen et al. [33] & Denmark & Retrospective & Ligation & Symptoms only & Yes & 46 & 6.5 & 5 \\
\hline Spanos et al. [13] & USA & Prospective & Ligation & Universal scoping & Yes & 41 & 19.5 & 6 \\
\hline Spanos et al. [13] & USA & Prospective & Clip & Universal scoping & Yes & 27 & 18.5 & 6 \\
\hline Vanamo et al. [34] & Finland & Prospective & Ligation & Symptoms only & No & 110 & 6.4 & 5 \\
\hline Vida et al. [35] & Italy & Prospective & Clip & Symptoms only & No & 150 & 0.7 & 6 \\
\hline Villa et al. [13] & France & Retrospective & Clip & Selective scoping & No & 721 & 2.5 & 5 \\
\hline Villa et al. [13] & France & Retrospective & Clip & Selective scoping & Yes & 22 & 13.6 & 5 \\
\hline Zbar et al. [4] & USA & Retrospective & Ligation & Selective scoping & No & 81 & 7.4 & 6 \\
\hline
\end{tabular}

${ }^{\text {a } V o c a l ~ c o r d ~ p a r a l y s i s ~ w a s ~ d i a g n o s e d ~ b a s e d ~ o n ~ s y m p t o m s ~ o n l y ~}$

${ }^{\mathrm{b}}$ Only symptomatic patients had laryngoscopy postoperatively to confirm vocal cord paralysis

${ }^{\mathrm{c}}$ All patients were scoped with laryngoscopy postoperatively

in premature newborns (Table 3). The overall pooled incidence of VCP in this population was $11.2 \%$ (95\%CI 7.0-16.3). Premature infants were more likely to develop VCP after surgical ligation (11.7\%; [95\%CI 6.9-17.5]) than surgical clipping (6.8\%; [95\%CI 0.7-16.9]). Subgroup analysis on geographical origin showed that VCP in premature patients seems to occur more frequently in
North America (14.0\%; [95\%CI 8.6-20.5]) than Europe (8.2\%; [95\% CI 2.5-16.4]).

\section{Incidence of VCP in Non-premature Patients}

Ten studies ( $n=2874$ patients) reported extractable data on the incidence of VCP after PDA closure in non-premature 
Table 2 Overall incidence of vocal cord paralysis after patent ductus arteriosus closure

\begin{tabular}{|c|c|c|c|c|}
\hline Subgroup & $\begin{array}{l}\text { Number of studies (number } \\
\text { of subjects) }\end{array}$ & $\begin{array}{l}\text { Pooled incidence of VCP after PDA } \\
\text { closure: } \%(95 \% \mathrm{CI})\end{array}$ & $I^{2}(\%)$ & $\begin{array}{l}\text { Cochran's } \\
\mathrm{Q}, p \text { value }\end{array}$ \\
\hline Overall & 33 (4887) & $7.9(5.3-10.9)$ & 91.1 & $<0.001$ \\
\hline \multicolumn{5}{|l|}{ Method of PDA closure } \\
\hline Surgical ligation & $20(1805)$ & $11.1(7.2-15.8)$ & 86.5 & $<0.001$ \\
\hline Surgical clipping & $11(2926)$ & $2.4(1.3-3.9)$ & 69.0 & 0.001 \\
\hline \multicolumn{5}{|l|}{ Method to assess for VCP } \\
\hline Universal laryngoscopy scoping $^{\mathrm{a}}$ & $7(291)$ & $24.2(14.5-35.3)$ & 75.0 & 0.001 \\
\hline Selective laryngoscopy scoping ${ }^{\mathrm{b}}$ & $10(1770)$ & $9.1(4.2-15.6)$ & 92.4 & $<0.001$ \\
\hline Symptoms scoping $^{c}$ & $15(2715)$ & $2.2(1.3-3.3)$ & 50.3 & 0.013 \\
\hline \multicolumn{5}{|l|}{ Geographical origin } \\
\hline Asia & $2(1358)$ & $1.0(0.5-1.6)$ & 0.00 & 0.582 \\
\hline Europe & $11(1732)$ & $4.5(2.3-7.3)$ & 77.7 & $<0.001$ \\
\hline North America & $17(1497)$ & $11.5(7.4-16.5)$ & 84.5 & $<0.001$ \\
\hline
\end{tabular}

$P D A$ patent ductus arteriosus, $V C P$ vocal cord paralysis

${ }^{a}$ All patients were scoped with laryngoscopy postoperatively to assess for VCP

${ }^{\mathrm{b}}$ Only symptomatic patients had laryngoscopy to assess for VCP

${ }^{\mathrm{c}} \mathrm{VCP}$ was diagnosed only based on symptoms

patients (Table 4). The overall pooled incidence estimate in this population was $3.0 \%$ (95\% CI 1.5-4.9). Again, surgical ligation resulted in significantly higher incidence of VCP (8.6\%; [95\% CI 5.0-13.0]) than surgical clipping (1.5\%; [95\%CI 0.9-2.3]). Subgroup analysis on geographical origin showed that VCP in non-premature patients seems to occur more frequently in North America (7.1\% [95\%CI 2.2-14.4]) than other regions.

\section{Duration of Vocal Cord Paralysis}

Overall, 10 studies ( $n=121$ patients with VCP) analyzed the duration of VCP after PDA closure. A total of $72.3 \%$ $\left(95 \%\right.$ CI $\left.30.8-100.0 ; I^{2}=92.0 ; p<0.001\right)$ of patients developed transient VCP. In premature newborns (five studies, 82 patients with VCP), the majority $(64.9 \%$; 95\% CI $\left.20.2-100.0 \% ; I^{2}=84.5 ; p<0.001\right)$ suffered from persistent VCP. Lastly, an analysis of six studies ( $n=46$ patients with VCP) on non-premature patients showed that these patients more often had transient VCP $(83.4 \%$; 95\%CI 71.5-92.8\%; $\left.I^{2}=0.0 ; p=0.631\right)$.

\section{Risk Factors of VCP}

\section{Birth Weight}

Six studies ( $n=321$ subjects) compared the birth weight between preterm infants with VCP and those without VCP (Table 5). It should be noted that birth weight in preterm infants with VCP was significantly lower than those without
$\mathrm{VCP}(\mathrm{WMD}=-149.03 \mathrm{~g} ; 95 \% \mathrm{CI}-269.02$ to $-29.05 \mathrm{~g}$; $p=0.02)$.

\section{Gestational Age}

Six studies ( $n=321$ subjects) reported the gestational age of preterm infants with and without VCP. As shown in Table 5, gestational age in preterm infants with VCP was significantly lower than those without VCP $(\mathrm{WMD}=-1.21$ weeks; $95 \%$ CI -1.79 to -0.63 weeks; $P<0.01)$.

\section{Weight at Ligation}

Four studies ( $n=287$ subjects) compared the weight at ligation between preterm infants with and without VCP. Pooled results in Table 5 indicate that weight at ligation in preterm infants with VCP was lower than those without VCP (WMD $=-258.00 \mathrm{~g} ; 95 \% \mathrm{CI}-548.15$ to $-32.15 \mathrm{~g}$; $p=0.08$ ); however, the difference was not significant.

\section{Days of Life at Ligation}

Four studies ( $n=224$ subjects) compared the days of life at ligation between preterm infants with and without VCP. Table 5 shows that the total days of life at ligation in preterm infants with VCP was shorter than those without VCP $(\mathrm{WMD}=-8.96$ days; $95 \% \mathrm{CI}-26.17$ to 8.25 days; $p=0.31$ ); however, the difference was not significant. 


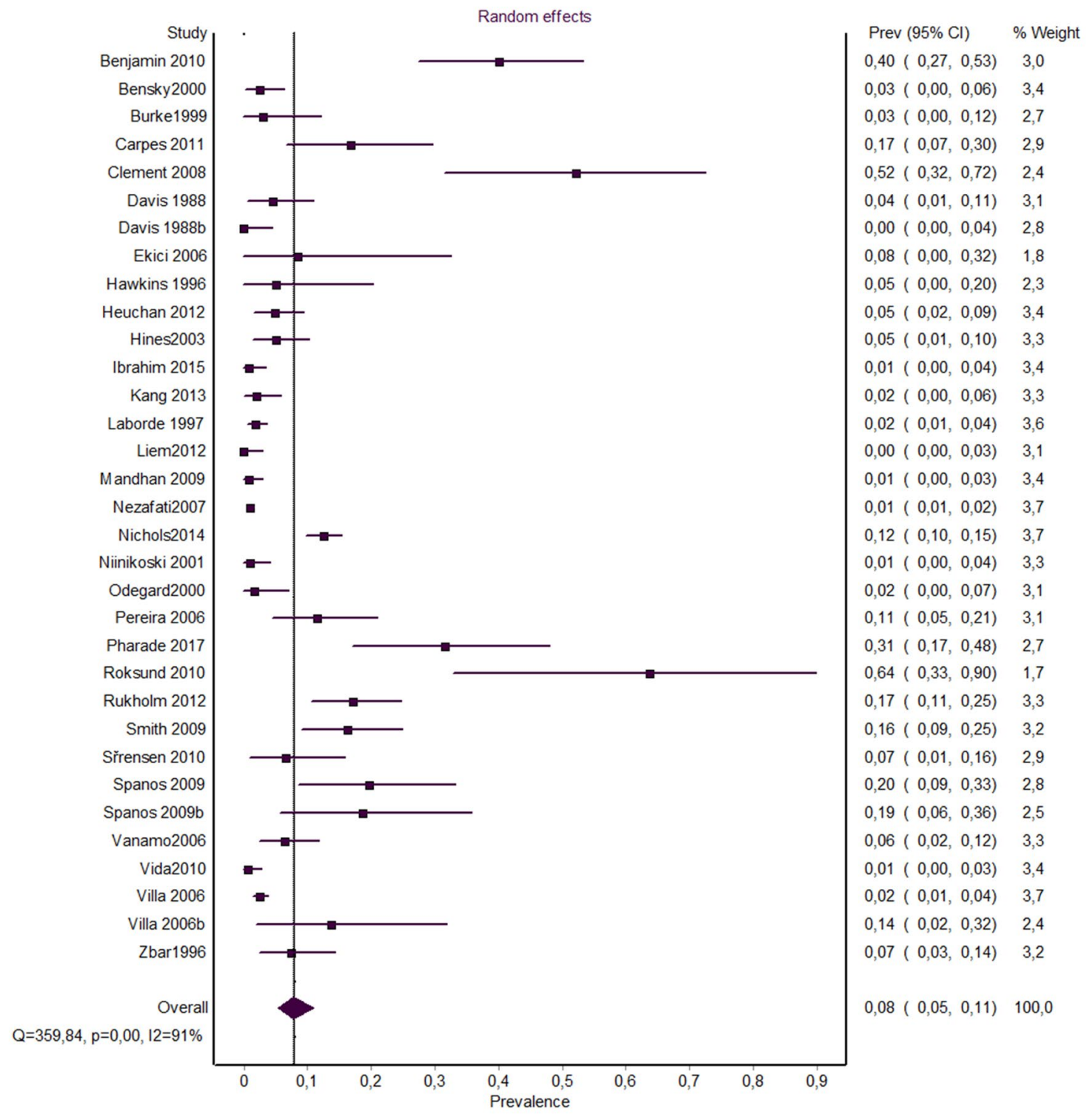

Fig. 2 Forest plot for overall pooled incidence rate of vocal cord paralysis

Table 3 Incidence of vocal cord paralysis after patent ductus arteriosus closure in premature / low birth weight patients

\begin{tabular}{lllrr}
\hline Subgroup & $\begin{array}{l}\text { Number of studies } \\
\text { (number of subjects) }\end{array}$ & $\begin{array}{l}\text { Pooled incidence of VCP after } \\
\text { PDA closure: \% (95\% CI) }\end{array}$ & $I^{2}(\%)$ & $\begin{array}{l}\text { Cochran's } \\
\text { Q, } p \text { value }\end{array}$ \\
\hline Overall & $22(1895)$ & $11.2(7.0-16.3)$ & 89.2 & $<0.001$ \\
$\begin{array}{l}\text { Method of PDA closure } \\
\text { Surgical ligation }\end{array}$ & $16(1552)$ & $11.7(6.9-17.5)$ & 89.0 & $<0.001$ \\
$\begin{array}{l}\text { Surgical clipping } \\
\text { Geographical origin }\end{array}$ & $4(187)$ & $6.8(0.7-16.9)$ & 73.5 & 0.010 \\
Europe & $7(419)$ & $8.2(2.5-16.4)$ & 81.3 & $<0.001$ \\
North America & $12(1176)$ & $14.0(8.6-20.5)$ & 85.3 & $<0.001$ \\
\hline
\end{tabular}

$P D A$ patent ductus arteriosus, $V C P$ vocal cord paralysis 
Table 4 Vocal cord paralysis after patent ductus arteriosus closure in non-premature patients

\begin{tabular}{llllc}
\hline Subgroup & $\begin{array}{l}\text { Number of studies } \\
\text { (number of subjects) }\end{array}$ & $\begin{array}{l}\text { Pooled incidence of VCP after } \\
\text { PDA closure: \% (95\% CI) }\end{array}$ & $I^{2}(\%)$ & $\begin{array}{l}\text { Cochran's } \\
\mathrm{Q}, p \text { value }\end{array}$ \\
\hline $\begin{array}{l}\text { Overall } \\
\text { Method of PDA closure }\end{array}$ & $3.0(1.5-4.9)$ & 77.7 & $<0.001$ \\
$\quad \begin{array}{l}\text { Surgical clipping } \\
\text { Surgical ligation }\end{array}$ & $6(2621)$ & $1.5(0.9-2.3)$ & 59.4 & 0.043 \\
Geographical origin & & $8.6(5.0-13.0)$ & 18.3 & 0.299 \\
Asia & $2(1358)$ & $1.0(0.5-1.6)$ & & \\
Europe & $4(1313)$ & $2.4(1.1-4.1)$ & 0.00 & 0.582 \\
North America & $4(203)$ & $7.1(2.2-14.4)$ & 60.0 & 0.059 \\
\hline
\end{tabular}

$P D A$ patent ductus arteriosus, $V C P$ vocal cord paralysis

Table 5 Risk factors and comorbidities in premature infants/low birth weight infants for vocal cord paralysis after patent ductus arteriosus closure

\begin{tabular}{|c|c|c|c|c|c|c|}
\hline Risk factor/comorbidity & $\begin{array}{l}\text { Number of studies } \\
\text { included (number of } \\
\text { patients) }\end{array}$ & $\begin{array}{l}\text { Type of } \\
\text { outcome } \\
\text { calculation }\end{array}$ & Value of outcome analysis (95\% CI) & $p$ value & $I^{2}(\%)$ & $\begin{array}{l}\text { Cochran's } \\
\mathrm{Q}, p \text { value }\end{array}$ \\
\hline Birth weight & $6(321)$ & WMD & $-149.03 \mathrm{~g}(-269.02$ to -29.05$)$ & 0.02 & 90.3 & $<0.001$ \\
\hline Gestational age & $6(321)$ & WMD & -1.21 week $(-1.79$ to -0.63$)$ & $<0.01$ & 64.1 & 0.016 \\
\hline Weight at ligation & $4(287)$ & WMD & $-258.00 \mathrm{~g}(-548.15$ to 32.15$)$ & 0.08 & 96.8 & $<0.001$ \\
\hline Days of life at ligation & $4(224)$ & WMD & -8.96 days $(-26.17$ to 8.25$)$ & 0.31 & 98.0 & $<0.001$ \\
\hline Bronchopulmonary dysplasia & $4(200)$ & $\mathrm{RR}$ & $1.23(1.00-1.51)$ & 0.049 & 0.0 & 0.974 \\
\hline Duration of mechanical ventilation & $3(89)$ & WMD & 16.16 days (4.24 to 28.08 ) & $<0.01$ & 58.6 & 0.089 \\
\hline Gastrostomy tube insertion & $3(224)$ & $\mathrm{RR}$ & $1.22(1.00$ to 1.49$)$ & 0.03 & 57.8 & 0.069 \\
\hline
\end{tabular}

$C I$ confidence interval, $R R$ relative risk, $W M D$ weighted mean difference

\section{Comorbidities of VCP}

\section{Bronchopulmonary Dysplasia}

There was slight significant difference in the incidence of BPD in preterm infants with and without VCP, indicating that preterm infants with VCP were mildly more likely to suffer from BPD (four studies, $n=200$ subjects; RR $=1.23$; 95\%CI 1.00-1.51; $p=0.049 ; \mathrm{I}^{2}=0.0$, Table 5).

\section{Duration of Mechanical Ventilation}

The effect estimate revealed a significant difference in total days of mechanical ventilation between preterm infants with and without VCP (Table 5), showing that preterm infants with VCP needed prolonged mechanical ventilation (three studies, $n=89$ patients; WMD $=16.16$ days; 95\%CI 4.24-28.08 days; $p<0.01)$.

\section{Gastrostomy Tube Insertion}

Meta-analysis of three studies ( $n=224$ subjects) showed that there was slight significant difference in the incidence of gastrostomy tube insertion between preterm infants with and without VCP, indicating that preterm infants with VCP were more likely to require gastrostomy tube insertion $(\mathrm{RR}=1.22$; 95\%CI 1.00-1.49; $p=0.03$; Table 5).

\section{Discussion}

The ductus arteriosus is indispensable in the maintenance of fetal circulation. Failure to close in the first few days after birth may result in high morbidity and mortality if not treated correctly. Surgery is the standard method of closure in approximately a quarter of extremely low birth weight infants, as reported by the National Institute of Child Health and Human Development Neonatal Research Network [37]. Though the advantages of surgical closure of PDA and its short- and long-term efficacy and safety have been highlighted, multiple studies have demonstrated that VCP remains a common complication of these procedures. This meta-analysis assessed the incidence of VCP in various age populations and evaluated its risk factors and comorbidities in preterm infants following interventional closure of PDA.

To date, the true incidence of VCP after interventional PDA closure has been unclear. Our meta-analysis involving 4887 patients from 33 studies showed that the total incidence 
of VCP was (7.9\% [95\%CI 5.3-10.9]). The incidence of VCP after PDA closure was significantly higher in premature infants (11.2\% [95\% CI 7.0-16.3]) than in non-premature patients (3.0\% [95\% CI 1.5-4.9]), indicating premature infants are at a greater risk of VCP. Truong et al.'s study [6] illustrated that compared with term infants, preterm infants are less likely to recover vocal cord function. It could also be demonstrated in our study as persistent VCP occurred more frequently in premature newborns, while transient VCP was more commonly found in non-premature patients. A lower incidence of VCP after surgical clipping was found in this study, along with shorter operative time and lower risk of bleeding [25], should effectively encourage the use of this technique of surgical PDA closure in appropriately qualified patients.

The method of assessing and diagnosing VCP is of crucial importance in discerning the true incidence of this complication. The analysis of studies that scoped all patients postoperatively with laryngoscopy, regardless of the presence of laryngeal symptoms, showed significantly higher incidence of VCP (24.2\%) as compared to studies that assessed only symptomatic patients $(7.5 \%)$ or based diagnosis of VCP on symptoms alone $(2.0 \%)$. Though the majority of universal scoping studies were done on premature patients, which had a higher incidence of VCP to begin with, these findings suggest that VCP might be highly underestimated. This is particularly evident by the low pooled incidence of VCP in studies diagnosing patients only based on symptoms. Geographical differences may be partially attributed to the lack of studies conducting universal laryngoscopy scoping in Europe and Asia, thus underestimating the incidence of VCP in those continents.

Birth weight and gestational age were significantly associated with the occurrence of VCP. Even though the difference was not significant, the weight at ligation and days of life at ligation in preterm infants with VCP were lower than those without VCP. It is not unexpected, as the smaller and weaker infants are more likely to suffer from complication PDA surgical closure.

Preterm infants with VCP were more likely to have respiratory problems. The exact causal relationship between VCP and BPD remains unclear. Chronic microaspiration due to impaired airway protection following extubation could be a mechanism causing ongoing lung injury; however, it also is possible that infants with the most-severe lung disease are most likely to undergo surgical treatment of PDA [17]. Along with the development of BPD, the functional residual capacity has been shown to be reduced, which requires glottal closure to create positive-end expiratory pressure. Extubated infants with VCP and secondary glottic incompetence may experience decreased pulmonary function, leading to prolonged mechanical support to maintain functional residual capacity. Moreover, the high risk of aspiration for infants with VCP may induce lung injury and contribute to a prolonged duration of mechanical ventilation.

Swallowing difficulties are common manifestation of vocal cord dysfunction after cardiothoracic surgery, leading to significant feeding problems [38]. Compared with infants who did not have symptoms of VCP following PDA surgery, those with VCP were more likely to have ongoing problems with feeding and growth, thereby requiring total or supplemental tube feedings at hospital discharge.

Several limitations of this meta-analysis should be considered. First, despite the high incidence of VCP in the preterm infants following PDA surgery, there remains a lack of coordinated, high-quality studies in the literature. In addition, many included studies are limited by their retrospective design. The incidence of VCP may be highly underestimated because most asymptomatic patients did not undergo laryngoscopy and a large proportion of patients were diagnosed based on symptoms alone.

\section{Conclusions}

We report an overall VCP pooled incidence of $6.9 \%$ and high pooled incidence of VCP in premature infants (11.7\%). The data showed that VCP was most common after surgical ligation and was the highest in studies conducting universal laryngoscopy scoping. The risk factors for postoperative VCP in preterm infants included birth weight and gestational age. In addition, VCP was associated with the occurrence of BPD and gastrostomy tube insertion, as well as an increased duration of mechanical ventilation.

\section{Compliance with Ethical Standards}

Conflict of interest The authors declare that they have no conflict of interest.

Ethical Approval This article does not contain any studies with human participants or animals performed by any of the authors.

Open Access This article is distributed under the terms of the Creative Commons Attribution 4.0 International License (http://creativeco mmons.org/licenses/by/4.0/), which permits unrestricted use, distribution, and reproduction in any medium, provided you give appropriate credit to the original author(s) and the source, provide a link to the Creative Commons license, and indicate if changes were made.

\section{References}

1. Clyman R, Wickremasinghe A, Jhaveri N et al (2013) Enteral feeding during indomethacin and ibuprofen treatment of a patent ductus arteriosus. J Pediatr 163:406-411. https://doi.org/10.1016/j. jpeds.2013.01.057 
2. Clyman RI (2000) Ibuprofen and patent ductus arteriosus. N Engl J Med 343:728-730. https://doi.org/10.1056/NEJM20000907343 1009

3. Niinikoski H, Alanen M, Parvinen T et al (2001) Surgical closure of patent ductus arteriosus in very-low-birth-weight infants. Pediatr Surg Int 17:338-341. https://doi.org/10.1007/s003830000515

4. Zbar RIS, Chen AH, Behrendt DM et al (1996) Incidence of vocal fold paralysis in infants undergoing ligation of patent ductus arteriosus. Ann Thorac Surg 61:814-816. https://doi. org/10.1016/0003-4975(95)01152-8

5. Benjamin JR, Smith PB, Cotten CM et al (2010) Long-term morbidities associated with vocal cord paralysis after surgical closure of a patent ductus arteriosus in extremely low birth weight infants. J Perinatol 30:408-413. https://doi.org/10.1038/jp.2009.124

6. Truong MT, Messner AH, Kerschner JE et al (2007) Pediatric vocal fold paralysis after cardiac surgery: rate of recovery and sequelae. Otolaryngol Neck Surg 137:780-784. https://doi. org/10.1016/j.otohns.2007.07.028

7. Tantraworasin A, Woragidpoonpol S, Chuaratanapong S et al (2012) Timing of surgical closure of patent ductus arteriosus in preterm neonates? Asian Cardiovasc Thorac Ann 20:12-18. https ://doi.org/10.1177/0218492311430356

8. Roksund OD, Clemm H, Heimdal JH et al (2010) Left vocal cord paralysis after extreme preterm birth, a new clinical scenario in adults. Pediatrics 126:e1569-e1577. https://doi.org/10.1542/ peds.2010-1129

9. Loney PL, Chambers LW, Bennett KJ et al (1998) Critical appraisal of the health research literature: prevalence or incidence of a health problem. Chronic Dis Can 19:170-176

10. Higgins JP, Green S (2008) Cochrane handbook for systematic reviews of interventions. Wiley, Chichester

11. Davis JT, Baciewicz FA, Suriyapa S et al (1988) Vocal cord paralysis in premature infants undergoing ductal closure. Ann Thorac Surg 46:214-215. https://doi.org/10.1016/S0003-4975(10)65901 $-2$

12. Spanos WC, Brookes JT, Smith MC et al (2009) Unilateral vocal fold paralysis in premature infants after ligation of patent ductus arteriosus: vascular clip versus suture ligature. Ann Otol Rhinol Laryngol 118:750-753. https://doi.org/10.1177/0003489409 11801011

13. Villa E, Folliguet T, Magnano D et al (2006) Video-assisted thoracoscopic clipping of patent ductus arteriosus: close to the gold standard and minimally invasive competitor of percutaneous techniques. J Cardiovasc Med 7:210-215. https://doi.org/10.2459/01. JCM.0000215275.55144.17

14. Bensky AS, Raines KH, Hines MH (2000) Late follow-up after thoracoscopic ductal ligation. Am J Cardiol 86:360-361

15. Burke RP, Jacobs JP, Cheng W et al (1999) Video-assisted thoracoscopic surgery for patent ductus arteriosus in low birth weight neonates and infants. Pediatrics 104:227-230

16. Carpes LF, Kozak FK, Leblanc JG et al (2011) Assessment of vocal fold mobility before and after cardiothoracic surgery in children. Arch Otolaryngol Neck Surg 137:571. https://doi. org/10.1001/archoto.2011.84

17. Clement WA, El-Hakim H, Phillipos EZ, Coté JJ (2008) Unilateral vocal cord paralysis following patent ductus arteriosus ligation in extremely low-birth-weight infants. Arch Otolaryngol Neck Surg 134:28. https://doi.org/10.1001/archoto.2007.2

18. Ekici F, Atasay B, Günlemez A et al (2006) Management of patent ductus arteriosus in preterm infants. Anadolu Kardiyol Derg 6:28-33

19. Heuchan AM, Hunter L, Young D (2012) Outcomes following the surgical ligation of the patent ductus arteriosus in premature infants in Scotland. Arch Dis Child Fetal Neonatal Ed 97:F39_ F44. https://doi.org/10.1136/adc.2010.206052
20. Hines MH, Raines KH, Payne RM et al (2003) Video-assisted ductal ligation in premature infants. Ann Thorac Surg 76:14171420; discussion 1420

21. Ibrahim MH, Azab AA, Kamal NM et al (2015) Outcomes of early ligation of patent ductus arteriosus in preterms, multicenter experience. Medicine (Baltimore) 94:e915. https://doi.org/10.1097/ MD.0000000000000915

22. Kang S-L, Samsudin S, Kuruvilla M et al (2013) Outcome of patent ductus arteriosus ligation in premature infants in the East of England: a prospective cohort study. Cardiol Young 23:711-716. https://doi.org/10.1017/S1047951112001795

23. Laborde F, Folliguet TA, Etienne PY et al (1997) Video-thoracoscopic surgical interruption of patent ductus arteriosus. Routine experience in 332 pediatric cases. Eur J Cardiothorac Surg 11:1052-1055

24. Liem NT, Tuan TM, Linh N Van (2012) A safe technique of thoracoscopic clipping of patent ductus arteriosus in children. J Laparoendosc Adv Surg Tech 22:422-424. https://doi.org/10.1089/ lap.2011.0454

25. Mandhan P, Brown S, Kukkady A, Samarakkody U (2009) Surgical closure of patent ductus arteriosus in preterm low birth weight infants. Congenit Heart Dis 4:34-37. https://doi.org/10. 1111/j.1747-0803.2008.00241.x

26. Nezafati MH, Soltani G, Vedadian A (2007) Video-assisted ductal closure with new modifications: minimally invasive, maximally effective, 1,300 cases. Ann Thorac Surg 84:1343-1348. https:// doi.org/10.1016/j.athoracsur.2007.04.077

27. Nichols BG, Jabbour J, Hehir DA et al (2014) Recovery of vocal fold immobility following isolated patent ductus arteriosus ligation. Int J Pediatr Otorhinolaryngol 78:1316-1319. https://doi. org/10.1016/j.ijporl.2014.05.019

28. Odegard KC, Kirse DJ, del Nido PJ et al (2000) Intraoperative recurrent laryngeal nerve monitoring during video-assisted throracoscopic surgery for patent ductus arteriosus. J Cardiothorac Vasc Anesth 14:562-564

29. Pereira KD, Webb BD, Blakely ML et al (2006) Sequelae of recurrent laryngeal nerve injury after patent ductus arteriosus ligation. Int J Pediatr Otorhinolaryngol 70:1609-1612. https:// doi.org/10.1016/j.ijporl.2006.05.001

30. Pharande P, Karthigeyan S, Walker K et al (2017) Unilateral vocal cord paralysis after surgical closure of a patent ductus arteriosus in extremely preterm infants. J Paediatr Child Health. https://doi. org/10.1111/jpc. 13632

31. Rukholm G, Farrokhyar F, Reid D (2012) Vocal cord paralysis post patent ductus arteriosus ligation surgery: risks and co-morbidities. Int J Pediatr Otorhinolaryngol 76:1637-1641. https://doi. org/10.1016/j.ijporl.2012.07.036

32. Smith ME, King JD, Elsherif A et al (2009) Should all newborns who undergo patent ductus arteriosus ligation be examined for vocal fold mobility? Laryngoscope 119:1606-1609. https://doi. org/10.1002/lary.20148

33. Sørensen CM, Steensberg JN, Greisen G (2010) Surgical ligation of patent ductus arteriosus in premature infants. Dan Med Bull 57:A4160

34. Vanamo K, Berg E, Kokki H, Tikanoja T (2006) Video-assisted thoracoscopic versus open surgery for persistent ductus arteriosus. J Pediatr Surg 41:1226-1229. https://doi.org/10.1016/j.jpeds urg.2006.03.002

35. Vida VL, Rubino M, Bottio T et al (2004) Thoracoscopic closure of the patent arterial duct. Cardiol Young 14:164-167. https://doi. org/10.1017/S1047951104002082

36. Hawkins JA, Minich LL, Tani LY et al (1996) Cost and efficacy of surgical ligation versus transcatheter coil occlusion of patent ductus arteriosus. J Thorac Cardiovasc Surg 112:1634-1639. https ://doi.org/10.1016/S0022-5223(96)70022-3 
37. Stevenson DK, Wright LL, Lemons JA et al (1998) Very low birth weight outcomes of the National Institute of Child Health and Human Development Neonatal Research Network, January 1993 through December 1994. Am J Obstet Gynecol 179:1632-1639
38. Sachdeva R, Hussain E, Moss MM et al (2007) Vocal cord dysfunction and feeding difficulties after pediatric cardiovascular surgery. J Pediatr 151:312-315.e2. https://doi.org/10.1016/j.jpeds .2007 .03 .014 